\title{
Phraseology, Corpus Linguistics and Lexicography. Papers from Phraseology 2009 in Japan

\author{
Edited by Katsumasa Yagi and Takaaki Kanzaki \\ Kwansei Gakuin University Press \\ Nishinomiya City, Hyogo Prefecture 2009, pp. 234
}

The volume Phraseology, Corpus Linguistics and Lexicography. Papers from Phraseology 2009 in Japan contains papers based on the presentations delivered at the conference Phraseology 2009 in Japan, which was a five-day event held in the city of Nishinomyia, Japan from July $7^{\text {th }}$ to $11^{\text {th }}, 2009$, organized thanks to Professor Katsumasa Yagi's initiative. The book reviewed is composed of four parts: the Preface by Professor Katsumasa Yagi, Lexicography, Corpus Linguistics, Phraseology, Phraseology and Culture.

The first part of the book, comprising two articles, starts with the paper by František Čermák titled Types of Language Nomination: Universal, Typology and Form. The author focuses on language nomination and examines ten common nouns in English, Finnish and Czech (head, nose, eye, tongue, heart, dog, cat, tree, stone, water and their cross-linguistic equivalents). The data analyzed was excerpted from very large dictionaries. Three of universal language types have been chosen: isolating, agglutinative and inflectional. The research study shows that the extent of polysemy is smallest for inflectional languages and largest for isolating languages. It remains in contrast with derivation, which has a very small representation for isolating languages and a very large one in inflectional languages. Compounding is most common in agglutinative languages.

The other paper on lexicography in the volume is the one by Katsumasa Yagi. In the paper titled English Lexicography in Japan - History and the State of the Art the author presents the historical development of English-Japanese dictionaries in Japan. The detailed presentation is fol- 
lowed by the description of the typical dictionaries currently available on the market. Common practices observed in learner's English-Japanese dictionaries are presented. Special attention is drawn to highly developed phraseological information given in the dictionaries at issue. Furthermore, it is discussed how to update the English dictionaries. The future perspectives of English lexicography in Japan are also outlined, with an emphasis on the need of international cooperation, especially among Asian neighbours, in the area of compiling English dictionaries on a bilingual basis.

The second part of the volume reviewed, Corpus Linguistics, is composed of four papers. František Čermák's paper titled The Case of the Czech National Corpus: Its Design, Development and Current State contains the presentation of the Czech National Corpus, which nowadays is one of the largest in Europe. The types of data included are discussed as well as the organization of the whole project and some of its processing. The idea of representativeness is presented and selected technical and linguistic problems are analyzed as well. Moreover, various corpora completed within the Czech National Corpus project, which can be accessed on the Internet, are presented.

Atsuko Umesaki's paper Corpus-based Collocation Studies in English: From lexico-grammar to discourse contains a brief account of the definition of the term collocation and the analysis of some examples of corpus-based collocation studies. The author examines differences of meaning in synonyms and identifying relationships between grammatical patterns and meaning on the example of collocation data from large-scale corpora. Thanks to corpora, the units selected can be analysed in relation to a discourse context.

Naohiro Takizawa in his paper titled Collocation and phraseology of present-day Japanese focuses on the analysis of collocations and phraseological units. The author does his research study basing on large-scale corpora. He draws attention to the lack of a well-balanced corpus of the present-day Japanese and presents a project currently done, the aim of which is to build a large-sized corpus of the Japanese language. The author emphasizes the importance of using large-scale corpora in research on phraseological units.

The paper written by Shin'ichiro Ishikawa, the title of which is Phraseology Overused and Underused by Japanese Learners of English: A Contrastive Interlanguage Analysis, is based on the method called contrastive interlanguage analysis. The author compares the usage and frequency 
of phraseological units excerpted from English essays written by Japanese students of the English language as well as English native speakers. Japanese students tend to overuse phraseologisms with the first person pronouns, contractions and frequent idiomatic expressions, while they underuse possible lexical variants and prepositional phrases.

The third part of the volume reviewed, titled Phraseology, contains as many as six papers. The first of them, titled Identification of Idioms and Phrasemes, is written by František Čermák. The author proposes the ways how to identify idioms in texts. The paper contains a brief analysis of current views and criteria from the perspective of structuralism, followed by a presentation of their paradigmatic and syntagmatic aspects. Moreover, some new concepts are presented, including that of virtual and collocational paradigms.

The focal issue of the paper by Joanna Szerszunowicz, titled Linguo-cultural analyses of European phraseological units in a contrastive perspective, is the presentation of research on phraseology done within conceptual studies and cognitive linguistics. The author discusses the flaws and merits of linguo-cultural analyses in a contrastive perspective and presents theoretical significance and practical applications of such research studies.

Katsumasa Yagi's paper titled English Phraseology in the Japanese Context draws attention to the place of English phraseology in Japanese studies. He emphasizes that despite the fact that phraseology may seem quite new to many Japanese linguists, in fact, a number of works belonging to usage studies, written since the mid $19^{\text {th }} \mathrm{c}$., are based on what are now called phraseological studies. The aim of the paper is to present the achievements of Japanese scholars in linguistic research on the English language and discuss their importance on the background of current trends if phraseology.

The aim of the paper The principle of least effort in present-day English: From 'pirated version' to 'pirate version' and related phenomena by Ai Inoue is to discuss the rule explaining the mechanism of derivation of the form 'without -ed' from the '-ed form'. The author analyses the semantic, phonetic and phonological features of -ed forms and forms without -ed. In conclusion, it is stated that the basic principle underlying the formation without -ed form from the -ed form is the principle of least effort.

Makoto Sumiyoshi in his paper titled That-taking Predicates in English: A Phraseological Approach analyses some that-taking verbs and other En- 
glish collocations in a phraseological perspective. The author's aim is to prove that a wider variety of verbs can take that-clause pattern than assumed up to now and that phraseological expressions such as nod one's head and keep one's fingers crossed can be followed by that-clause. It is argued that a pattern-based approach may be exploited in order to effectively explain phenomena in the English language.

The focal issue of the paper titled Various Functions of Kind of by Haixia Wang is the analysis of the expression kind of with a view to presenting it as a discourse marker with its various function in the process of communication. The analysis of the functions of the expression kind of encompasses functional clues, such as syntactic features, prosodic features and typically co-occurring words. The research study shows that the expression analysed functions as an imprecision marker and is also used to soften a strong opinion or claim common ground between the speaker and the listener.

The last part of the volume titled Phraseology and Culture contain one paper by Joanna Szerszunowicz. In the article titled On the Translation of Culture-Bound Units the author presents the translation techniques implemented in the case of culture-specific phraseological units. The techniques are discussed on the example of selected Polish units and their English translation equivalents.

The volume of papers reviewed reflects focal issues of linguistic research studies currently done across continents, which results in offering the reader a broad perspective. The authors of the papers collected investigate a variety of language phenomena from different points of view, implementing various methods and analyzing well-selected material. The volume gives an insight into a number of problems discussed by the contributors. Therefore, to sum up, it can be concluded the book is of great importance for those interested in phraseology, corpus linguistics and lexicography. 